\title{
Intervention Against the Excessive Use of Anxiolytica and Hypnotica in Two General Practices
}

\author{
Viggo Rask Kragh Jørgensen* and Birgit Signora Toft
}

Medicine Team Central Denmark Region, Lagårdvej 12, 7500 Holstebro, Denmark

\begin{abstract}
This publication describes the successful reduction in the use of benzodiazepines as anxiolytics by $87 \%$, as well as the reduction in the use of benzodiazepines and cyclopyrrolones as hypnotics by $92 \%$, for two general practitioners over a period of three years.
\end{abstract}

The measures implemented were few and simple:

- Cessation of telephone prescriptions.

- Issue of prescriptions only following consultation.

- Prescriptions limited to a single months requirements.

At each monthly consultation, the patient as well as the practitioner was required to re-evaluate the need and extent of the subsequent prescriptions.

During the first three months, only four to five additional consultancies per week per 1000 patients were required. Subsequently, this number was stabilized at approximately one additional consultancy per week.

The routine implementation of the aforementioned simple procedure is to be recommended for the ordination of BD and $\mathrm{CP}$ drugs, as the effect is both significant and persistent.

Keywords: Addiction, benzodiazepines, cyclopyrrolones, dependency inducing drugs, drug misuse, general practice.

\section{INTRODUCTION}

It has been considered virtually impossible for general practices to achieve a reduction in the consumption of dependency-inducing drugs such as benzodiazepines (BD) and cyclopyrrolones (CP). Regulations for the prescription of the drug groups are virtually identical in e.g. England, Norway and Denmark [1-3]. The drugs should only be prescribed for a few weeks, after which a re-evaluation must take place. In Denmark, there were 452.500 users of these medications during 2008 , constituting $8.3 \%$ of the population.

The problem of excessive $\mathrm{BD}$ and $\mathrm{CP}$ consumption is not exclusively Danish, as e.g. it was revealed in 2000 that $9.6 \%$ of a 1000-subject randomized sample of the Lebanese population had consumed these medications during the month preceding the study [4], while $6.5 \%$ of the adult population of Norway had a daily consumption of BD and CP [2]. The high prevalence of benzodiazepine use remains an important worldwide issue [5, 6]. Accordingly, in 2003 the Danish Minister for the Interior and Health instructed general practitioners to reduce prescriptions of $\mathrm{BD}$ and $\mathrm{CP}$ by $50 \%$, otherwise a tightened supervision would be implemented. In Denmark, implementation of this initiative has been characterized by apathy, as practitioners have considered it

\footnotetext{
*Address correspondence to this author at the Ærøvej 1b, 7680 Thyborøn, Denmark; Tel: Work 978323 00, Private 978324 93; Fax: 978320 57; E-mail: VKJ@DADLNET.DK
}

impossible to live up to the requirements of the circular. Most practitioners have been dismissive, or have ignored the circulars. No effective method to implement a reduction has been introduced. After the first year the national reduction was $1.5 \%$, subsequently increasing to $4.6 \%$ in 2006 [7].

This attention is professionally justified, as these drugs are extremely addictive, and are associated with significant abstinence problems, while the consumption of these drugs leads to serious side effects of which the most common are those influencing intellectual functions. Adaptation to these side effects takes place to a very limited degree, even after long periods of use of these drugs. The elderly are especially vulnerable, due to altered elimination. Among consumers of $\mathrm{BD}$ and $\mathrm{CP}$ aged over 65 years, the risk of falls with subsequent hip fractures is increased by $50-110 \%[8,9]$. These drugs are considered to represent a danger for users of motor vehicles, and a study of elderly patients has shown a $2-5$ times increase in the risk of traffic accidents. This risk of traffic accidents is of the same magnitude as for those who operate motor vehicles under the influence of alcohol [10]. A significant excess mortality is observed among users of these drugs [8-11].

In 2003, two practitioners in the Danish village Thyborøn, in cooperation with the Medical Health Officer Institution and the County Medicine Unit, decided to introduce the new regulations for the prescription of $\mathrm{BD}$ and $\mathrm{CP}$ drugs, for the benefit of their patients as well as to comply with national regulations. From the experience of former users of 
these drugs, it is known that quality of life increases significantly following the reduction in their consumption of drugs $[12,13]$. Initial results from Thyborøn revealed a reduction in the consumption of BD by $50 \%$, and in the consumption of CP by $75 \%$ over a 15 month period $[14,15]$. The results presented here represent a longer term, three year update on the effects of this intervention.

\section{MATERIALS AND METHODS}

Two general practices, comprising a patient base of approximately 2300 , introduced new regulations which were essentially in compliance with Danish directive CIR no. 12 13/01/2003 for the prescription of BD and CP drugs [3].

- Telephone prescriptions were eliminated.

- Issue of prescriptions only following personal attendance.

- Prescriptions limited to a single months requirements.

This lead to a situation, where practitioner and patient once a month were required to consider whether the level of consumption was appropriate, or whether consumption should be reduced.

The material compiled here originates from data reported by pharmacies to the Drug Statistics Register of the Danish National board of Health (Ordiprax) covering the sale of prescription drugs to private individuals [16]. For each prescription, the practitioner's identification code, the patient's central person registration (CPR) number and the products specific product identification number are registered, where the latter comprises the products anatomical therapeutic chemical (ATC) -code, package size as well as the total number of defined daily doses (DDD) in the package. The total number of DDD for each quarter is registered for each practitioner and for each drug group, and is defined as the assumed average maintenance dose per day for a drug used for its main indication in adults.

Ordiprax is divided into two categories: county data and medical practice data. Medical practice data comprises the individual practices prescriptions to own patients, redeemed at a Danish pharmacy, and is normally only visible to the practitioner.

Ordiprax data was received already standardized with respect to gender and age, relative to the reference (national) population. The level of error in the registered values in Ordiprax is 4\% [16] and this level of error will have no effects on the conclusions reached in this article.

With the exception of the severely physically or mentally ill, all users of BD and CP were included in the intervention. The term severe physical disorder covered patients suffering from a terminal disease, or patients where disease characteristics were such that the prescription of medical drugs was primarily performed by a specialist unit. Severe psychiatric disorders generally covered patients whose treatment has being monitored by a psychiatrist. The treatment of patients excluded from this study was not changed as a result of this project.

The reduction in prescriptions was described by the following: The total DDD for every 1.000 of the physicians own patients per quarter at the last quarter of 2006 is com- pared to the average DDD for the four quarters of 2003. Accordingly, the intervention covered a duration of three years. The intervention included the ATC-code classified N05CD (e.g. flunitrazepam and triazolam) hypnotic and N05BA (e.g. oxazepam and diazepam) anxiolytic benzodiazepines as well as N05CF hypnotic cyclopyrrolones (e.g. zopiclon and zolpidem).

\section{RESULTS}

The consumption of hypnotica of the benzodiazepine group (NO5CD) fell by $100 \%$ for practice 1 and by $55.6 \%$ for practice 2 (Fig. (1); $86.0 \%$ for both practices combined), while the consumption of anxiolytica of the benzodiazepine group (NO5BA) fell by $93.8 \%$ for practice 1 and by $82.9 \%$ for practice 2 (Fig. (2); $86.8 \%$ for both practices combined). The consumption of hypnotica of the cyclopyrrolone group (NO5CF) fell by $89,6 \%$ for practice 1 and by $95,6 \%$ for practice 2 (Fig. (3); $92.4 \%$ for both practices combined). After three years, the consumption of BD as anxiolytica was reduced by $86.8 \%$, while the combined consumption of BD and CP hypnotica was reduced by $91.6 \%$.

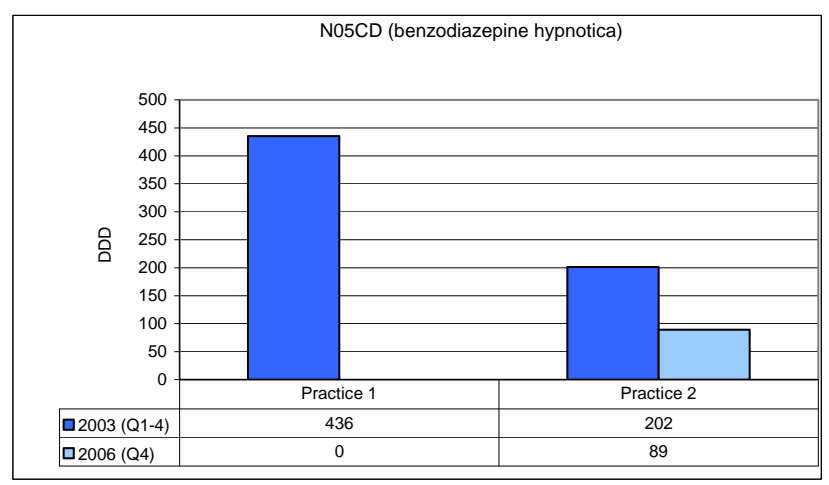

Fig. (1). The reduction in prescriptions, described as the decline in Defined Daily Dose (DDD) for every 1.000 of the physicians own patients for N05CD (the benzodiazepine group of hypnotics, e.g. flunitrazepam) for the last quarter of 2006 compared to the average DDD for the four quarters of 2003.

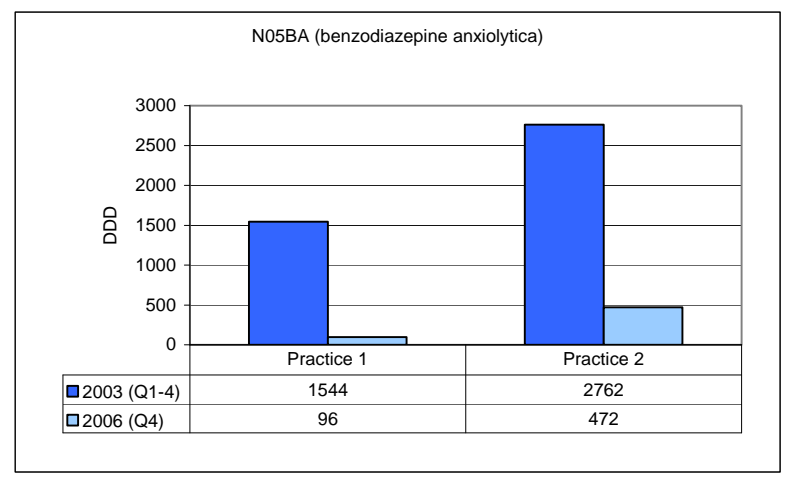

Fig. (2). The reduction in prescriptions, described as the decline in Defined Daily Dose (DDD) for every 1.000 of the physicians own patients for N05BA (the benzodiazepine group of anxiolytics, e.g. diazepam) for the last quarter of 2006 compared to the average DDD for the four quarters of 2003.

The intervention involved a total of 128 patients. Four patients chose to change practitioner as a consequence of the project. The increased burden to the practitioner was initially 


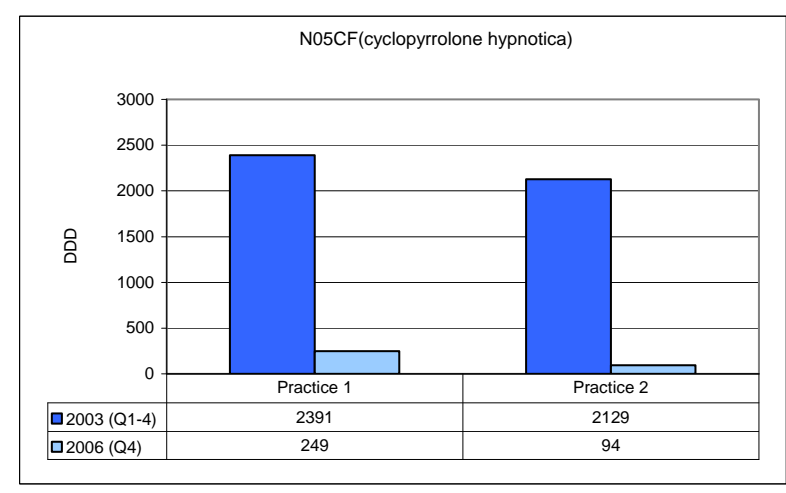

Fig. (3). The reduction in prescriptions, described as the decline in Defined Daily Dose (DDD) for every 1.000 of the physicians own patients for N05CF (cyclopyrrolones, e.g. zopiclon) for the last quarter of 2006 compared to the average DDD for the four quarters of 2003.

four to five additional consultations per week per 1000 patients. This number was subsequently reduced to approximately one additional consultancy per week, three years after the initiation of the intervention. No patients were hospitalized, and a single patient was referred to a psychiatrist as a consequence of the project. No patients developed serious withdrawal symptoms (e.g. suicidal impulses, abstinence cramps), as determined by specific questioning during the monthly consultation. Lesser withdrawal symptoms observed included anxiety, unrest, increased dream activity and insomnia as well as melancholic tendencies.

Most patients were able to reduce their consumption of the $\mathrm{BD}$ and $\mathrm{CP}$ medications originally prescribed without any need for detoxification. If patients were originally prescribed medications with a short half-life, problems could arise and, as a result of this, these prescriptions were initially changed to diazepam with a subsequent, controlled reduction in consumption.

\section{DISCUSSION}

Many methods have been used in an attempt to reduce the consumption of BD. In a Norwegian study [17] a significant reduction was observed in a group of users following the dissemination of written information together with an offer of assisted reduction from their practitioners. In a corresponding Danish study [18], information pamphlets and a questionnaire were sent to individual consumers of BD, in an attempt to make them reflect on their own situation and future consumption. This resulted in a significant decline in consumption. These findings are in accordance with an English study, where a $24 \%$ reduction was achieved merely by sending a letter to patients [19]. In a simple audit study [20] regarding the prescription of $\mathrm{BD}$ it was discovered that the number of consumers could be reduced by $16 \%$. In addition, studies reveal that focused and individualized efforts give remarkably good results [21].

In New York new rules were introduced in 1989 requiring that prescriptions of BD be written in triplicate on special forms. At the same time, practitioners were required to acquire and purchase the prescription forms. Prescriptions were to be copied in triplicate on special, serialized forms. The initiative reduced the consumption of $\mathrm{BD}$ by $30-60 \%$ [22].
Subsequently, an alarming increase in the prescription of alternative medication was observed. For example, in 1989 this leds to a $142 \%$ increase in the prescription of the antidepressant fluoxetin, an increase which was $33 \%$ higher than the national average. Similarly, a redistribution to the consumption of anxiolytica was observed, with e.g. the prescription of barbiturates increasing by $31 \%$, while chloral hydrate consumption increased by $136 \%$. In contrast to these projects, the current intervention is simple and easily implemented.

A limitation of the findings presented here is the scale of the intervention. Accordingly, a cost-benefit analysis of the intervention is not feasible. It should also be noted that the results are based on the actual ordination data for $\mathrm{BD}$ and $\mathrm{CP}$ for the specific practices and time periods, and that these data do not take into account patients excluded from the intervention, or patients joining or leaving either of the two practices.

The present intervention demonstrates that a reduction is in fact possible in general practice. One of the most important developments reported here is the fact that the previously reported reduction $[14,15]$ in the number of prescriptions of BD and CP could be maintained and expanded. The few and simple methods used gave far greater results and proceeded far easier than either of the practitioners had expected. The results presented here indicate that this simple intervention is, in contrast to other studies, also effective in the long term. To understand this apparent discrepancy, it is important to understand that long term success is dependant on the degree to which patients and practitioners are informed and convinced with respect to the intervention itself. Typically, Danish patients enjoy a high level of confidentiality and communication with their practitioners. Conversely, an intervention as described here may encounter different levels of success in societies with more (or less) authoritative patient-practitioner relationships, and additional resources may need to be spent on informing and convincing these patients in order to attain a higher level of understanding and accept. The required knowledge regarding drug reduction can be attained by any practitioner in the course of a few hours [23-25]. Our experience reveals that it is vital to maintain the monthly consultation in order to motivate both parties, to retain focus on the problem as well as to eliminate unnecessary discussions with patients.

The importance of a reduction of BD and CP underscored by an economic analysis from 1989 indicating that there is an increased annual cost for each dependent patient of 48,000 Euros in direct and indirect costs for the patient, and for society [26]. In addition, a reduction in traffic accidents is associated with a reduction of $\mathrm{BD}$ and $\mathrm{CP}$. Patients generally report having a better life with less addictive behavior and greater benefits in everyday family and social life, where patients may otherwise have had the feeling of having wasted a lot of years [12].

In the western part of Central Denmark Region, these issues have been successfully addressed and the model has been implemented. Initially, the rules were introduced in a smaller town, leading to an approximate half consumption over a 15 month period [26]. The regulations were intro- 
duced to practitioners with a patient base of 365.000 . This gave an estimated patient population of 18.000. The experiences gained were positive. These findings could also be interesting for decision makers in health care systems who are preparing new regulations for the prescription of $\mathrm{BD}$ and $\mathrm{CP}$. This is especially relevant when we see that the rules have already been implemented at the national level through the Danish guide dated 8 July 2008 [27].

Finally, the question of concomitant changes in prescriptions of antidepressants and antipsychotics during this intervention has been considered in previous articles [28, 29], where it is demonstrated that the intervention against BD and $\mathrm{CP}$ resulted in no significant increases in the total prescription volumes of antidepressants and antipsychotics.

\section{CONCLUSION}

We recommend the implementation of the following few and simple rules for the prescription of $\mathrm{BD}$ and $\mathrm{CP}$ in general practice:

- Telephone prescriptions should be eliminated.

- Issue of prescriptions only following personal attendance.

- Prescriptions limited to a single months requirements.

both for the benefit of patients and in order to bring prescription patterns in compliance with good clinical practice.

Ethical approval: Not required, as the intervention was not an experiment.

Contributors: VRKJ contributed to the development of the project and wrote the protocol. The intervention took place in part in his practice, and he subsequently wrote the manuscript. BST contributed to the conceptual development of the project and gave inspiration to the protocol while contributing with constructive criticism during the preparation of the manuscript.

\section{ACKNOWLEDGEMENTS}

Thanks are extended to dr. Hans Holmsgaard, Thyborøn, for his cooperation as well as for his willingness to contribute material.

Funding: VRKJ receives support from the Ministry of Health and Prevention pool for studies and initiatives related to drug issues, including compliance.

\section{REFERENCES}

[1] Benzodiazepines warning, Chief Medical Officer's Update 37, Patient Safety, Department of Health, January 2004. http:// www.benzo.org.uk/cmo.htm [Accessed 2009 December 6].

[2] Norwegian Board of Health Supervision. Addictive drugs. Prescription and justifiable. [In Norwegian] 14. September 2001 http://www.helsetilsynet.no/upload/publikasjoner/andrepublikasjon er/vanedannende_legemidler_forskrivning_forsvarlighet_ik-2755. pdf. [Accessed 2009 December 6].

[3] Communication regarding the prescription of addictive drugs. Directive CIR 12 from 13/01/2003. Copenhagen; [in Danish] Danish National Board of Health, 2003.

[4] Naja WJ, Pelissolo A, Haddad RS, Baddoura R, Baddoura C. A general population survey on patterns of benzodiazepine use and dependence in Lebanon. Act Psychiatr Scand 2000; 102(6): 429-31.
[5] Srisurapanont M, Critchley J, Garner P, Maneeton B, Wongpakaran $\mathrm{N}$. Interventions to reduce benzodiazepine prescribing. (Protocol) Cochrane Database Syst Rev 2005; 1: Art. No.: CD005172.

[6] Denis C, Fatseas M, Lavie E, Auriacombe M. Pharmacological interventions for benzodiazepine mono-dependence management in outpatient settings. Cochrane Database Syst Rev 2006; 3: Art. No.: CD005194.

[7] The Danish Medicines Agency. The consumption of benzodiazepines and benzodiazepine related drugs. http://www.dkma.dk/ 1024/visUKLSArtikel.asp?artikelID=11644 [Accessed 2009 December 6].

[8] Wang PS, Bohn RL, Glynn RJ, Mogun H, Avorn J. Zolpidem use and hip fractures in older people. J Am Geriatr Soc 2001; 49: 168590 .

[9] Cumming R, Le Couteur DG. Benzodiazepines and risk of hip fractures in older people. CNS Drugs 2003; 17: 825-37.

[10] Vester JC, Veldhuijzen DS, Volkerts ER. Residual effects of sleep medication on driving ability. Sleep Med Rev 2004; 8(4): 309-25.

[11] Warning to exercise great care when treating with antipsychotic drugs in combination with sleep and nerve medicine. National Board of Health [Danish] 29.11.2006. Available from: http://www.sst.dk/Nyheder/Seneste_nyheder/Indskaerp_antipsyk.as px?lang=da [Accessed 2009 February 28].

[12] Torper J, Steine S. Seponation of benzodiazepine- how is the experience of the users [In Norwegian]. Tidsskr Nor Laegeforen 2004; 124(18): 2342-4.

[13] Hansen EH, Helweg-Jørgensen S. Dependency on psycho pharmaceutics from a patient perspective [in Danish] Faculty of Pharmaceutical Sciences. Lægemiddelforskning 1999; 23.

[14] Jørgensen VRK, Toft BS, Fogh MS. Reducing the use of addictive drugs in clinical practice [Danish]. Ugeskr Laeger 2006; 168: 163640.

[15] Jørgensen VRK, Toft BS, Fogh MS. Reducing the use of benzodiazepines and cyclopyrrolones in clinical practice. Pharm Practi 2006; 4(2): 74-8

[16] Ordiprax: a tool for doctors and regions. Fact sheet from the Danish Medicines Agency [online]. Available from: URL: http:// www.ordiprax.dk [Accessed 2009 December 6].

[17] Mouland G. A letter to benzodiazepine users--an efficient way to reduce the prescription [in Norwegian]. Tidsskr Nor Laegeforen 1997; 117: 3097-3100

[18] Andreasen CM, Errebo-Knudsen L, Kristensen KA. Patient information might reduce the use of benzodiazepines in general practice [in Danish]. Ugeskr Laeger 1989; 145: 2968-70.

[19] Heather N, Bowie A, Ashton H, et al. Randomised controlled trial of two brief interventions against long-term benzodiazepine use: Outcome of intervention. Addict Res Theory 2004; 12: 141-54.

[20] Holden JD, Hughes IM, Tree A. Benzodiazepine prescribing and withdrawal for 3234 patients in 15 general practices. Fam Pract 1994; 11: 358-62.

[21] Ashton H. Benzodiazepine withdrawal: outcome in 50 patients. $\mathrm{Br}$ J Addict 1987; 82: 665-71.

[22] Weintraub M, Singh S, Byrne L, Maharaj K, Guttmacher L. Consequences of the 1989 New York State triplicate benzodiazepine prescription regulations. JAMA 1991; 266(17): 2392-7.

[23] Ashton CH. Benzodiazepines: how they work and how to withdraw. The Ashton manual. Aug. 2002. Available from: http:// www.benzo.org.uk/manual/index.htm [Accessed 2009 December 6].

[24] Danish Medicines Agency. Institute for Rational Pharmacotherapy. Benzodiazepine in general Practice [In Danish]. 2004; (1): 1-41. Available from http://www.redalyc.uaemex.mx/redalyc/pdf/690/ 69060304.pdf [Accessed 2009 December 6].

[25] Jørgensen VRK. Benzodiazepine reduction in practice [In Danish] Månedskr Prakt Lægegern 2006; 84: 333-9.

[26] Jørgensen VRK. An approach to reduce benzodiazepine and cyclopyrrolone use in general practice, A study based on a danish population. CNS Drugs 2007; 21(11): 947-55.

[27] Communication regarding the prescription of addictive drugs. Danish National Board of Health. July 2008. Available from: https://www.retsinformation.dk/Forms/R0710.aspx?id=117508 [Accessed 2009 December 6]. 
[28] Benzodiazepine reduction! Does this result in an increased consumption of antipsychotics? Lægemagasinet 2009; 9: 61-6.
[29] Benzodiazepine reduction does not lead to an increased consumption of antidepressives [In Danish]. Ugeskr Læger 2009; 171: 29993.

Received: December 21, 2009

(C) Jørgensen and Toft; Licensee Bentham Open .

This is an open access article licensed under the terms of the Creative Commons Attribution Non-Commercial License (http://creativecommons.org/licenses/by-nc/3.0/) which permits unrestricted, non-commercial use, distribution and reproduction in any medium, provided the work is properly cited. 